\title{
A FILOSOFIA NA ESCOLA REPRODUTORA
}

\author{
Grupo de Estudos e Pesquisa Filosofia: Por Quê?* \\ * Karyne Quintella \& Rui C. Mayer (orientador e organizador) \\ Instituto Superior de Estudos e Pesquisa em Filosofia e Ciências - ISEF \\ filpq.isef@pop.com.br
}

No concerto dos aparelhos ideológicos de Estado, um aparelho (...)

desempenha o papel dominante, muito embora não escutemos sua música, a tal ponto ela é silenciosa! Trata-se da Escola.

\section{Louis Althusser - 'Sobre as Relações de Produção' In Aparelhos Ideológicos de Estado}

Nas diversas contribuições à Filosofia do Ensino e da Educação 'encontra-se', perdida e quase esquecida, aquela do filósofo francês Louis Althusser: sua teoria e crítica da Ideologia (e da Reprodução). Freqüentemente recusado por ser mal entendido (e se fosse bem entendido, talvez mesmo fosse proibido!), o pensamento de Althusser, embora merecendo críticas que aqui não fazemos, mereceria também ser reconhecido em seu rigor e valor. Althusser estuda, critica, revisa e desenvolve o pensamento de Karl Marx, e o faz com originalidade; isto não é pouco. Althusser ensinou a, e pesquisou com Alain Badiou, influenciando profundamente o pensamento deste outro; e isto também não é pouco.

Por muito menos, alguns teóricos são 'festejados' no meio acadêmico. Tentaremos vingar-nos dessa injustiça histórica. Veremos que estamos nos referindo a um pensamento que chega mesmo a ser ofensivo ao nosso orgulho intelectual. Mas orgulho é pecado; portanto, somos mesmo uns mensageiros da salvação intelectual e acadêmica.

Neste texto, resultante de alguns 'estudos' promovidos pelo 'Filosofia: Por Quê?' Grupo do Instituto Superior de Estudos e Pesquisa em Filosofia e Ciências - pretendemos resgatar essa contribuição de Louis Althusser à Filosofia do Ensino e da Educação, num 'estudo crítico' acerca do 'ensino de filosofia' nas nossas (festejadas) escolas. De início, promovemos um certo resgate do pensamento althusseriano; depois, dele partindo, desenvolvemos algumas considerações, com ele e até além dele, justamente quanto às circunstâncias e limitações que a escola atual, como instituição de disciplinamento social (um aparelho ideológico), estabeleceria ao e no 'ensino de filosofia'. 


\section{Althusser e a Ideologia}

Althusser compreende a Ideologia em geral nos seguintes termos:

i) a Ideologia não teria uma história própria, pois não passa de devaneio consciente, produto arbitrário de uma imaginação desordenadamente a-histórica e que, como o inconsciente para Freud, "tem uma estrutura e um funcionamento tais que fazem dela uma realidade não-histórica, isto é, omni-histórica, no sentido em que esta estrutura e este funcionamento se apresentam da mesma forma imutável em toda a história" - (Althusser, 2001, p. 84);

ii) as 'ideologias' "têm uma existência material" - (idem, p. 88), ou seja, são formadas por aquelas práticas sociais necessárias para a reprodução das relações sociais de produção;

iii) as 'ideologias' operariam sobre e dentro dos indivíduos através de e como mecanismos ideológicos de sujeição, transformando "os indivíduos em sujeitos" (idem, p. 96);

iv) a função geral desses mecanismos seria a de sujeitar os indivíduos às exigências da produção social e de suas relações conseqüentes, fazendo-os crer na naturalidade da existência dessas relações, bem como na naturalidade dos indivíduos em ocupar nessas relações o lugar que ocupam / devem ocupar: "os indivíduos são sempre/já sujeitos" - (ibidem, p. 98).

A Ideologia seria então, de fato, uma estrutura funcional básica, um conjunto de engrenagens que determinaria as diversas manifestações ideológicas práticas: seus mecanismos sujeitariam os indivíduos, fazendo-os reconhecerem-se enquanto sujeitos sociais de uma concretude falsa e naturalmente sujeitados por ideais abstratos, mas tidos como 'reais' e absolutos.

Mas, se se trata de um conjunto de representações do mundo, a reclamar um valor 'V' ontognoseológico, já não se trata, a Ideologia mesma, de alguma abstração que se reduza ao imaginário: ao contrário, seria uma estruturação que funciona em e faz funcionar a sociedade. O nível ideológico, ou das "formas de consciência social", “... representa pois uma realidade objetiva, indispensável à existência de uma formação social; realidade objetiva, vale dizer, independente da subjetividade dos indivíduos que a ela estão submetidos" - (Althusser, 1986, pp. 46/47 - livre tradução do castelhano.) Em não dependendo da 'subjetividade' dos indivíduos, resta 'objetiva' (ou concreta) a Ideologia; ora, mais que independente em relação aos indivíduos, lhes é determinante, posto que os socializa, por sujeição a um imaginário cultural hegemônico. E essa 
socialização compulsória não se dá apenas no nível das idéias (do conhecimento, do pensar), mas tem um modo de 'existência concreta' nas práticas sociais e nas instituições: são os aparelhos ideológicos de Estado - os AIE's.

\section{A Aparelhagem Ideológica de Estado}

Para Althusser, o Estado em geral é composto pelo governo, a administração, o exército (i. é, as forças militares), a polícia, o sistema penal, o sistema judiciário, etc.; esses subconjuntos de elementares legais/administrativos formam o conjunto estatal de mecanismos repressivos, vale dizer, aqueles aparatos que podem e devem usar da força moral, psicológica ou física para reprimir resistências ou oposições, isso quando preciso ou "ao menos em situações limites" - (Althusser, 2001, p. 67): é o Aparelho Repressivo de Estado-ARE: o sistema institucional que centraliza e 'legitima' o Poder em sociedade.

Já os AIE's seriam aqueles aparelhos que, “... sob a forma de instituições distintas e especializadas" - (idem, p. 68), e sem se apresentarem como estatais mas, antes, como público-privados ou 'civis', necessariamente complementam o sistema estatal de dominação, através da Ideologia. Althusser nos dá um rol intuitivo, parcial e provisório dos AIE's: como jurídicos, familiares, políticos, religiosos, sindicais, de informação, culturais, e... escolares (ou do sistema educacional, que é o que mais nos interessa, - idem, p. 68).

Se o corpo repressivo do Estado teria por função coagir os indivíduos a aceitar e participar do domínio social de uma eventual 'aliança de classes' hegemônica, sobre as demais classes e os estamentos sociais todos, os AIE's têm a função ativa da "reprodução das relações de produção" - (idem, p. 78), que devem ser cridas em sua "naturalidade', já o vimos. E a reprodução das relações sociais deveria se dar não somente no nível da produção material, mas também no nível da re/produção ideológica. Como "os indivíduos são sempre/já sujeitos" - mesmo antes de nascer, o lugar do futuro indivíduo/sujeito já está reservado no AIE familiar -, eles ocupam seu lugar definido na produção e, enquanto sujeitos, "caminham por si" - (ibidem, p. 103). Pois os sujeitinhos, submetidos ao 'Sujeito', realizam a 'Sua' 'Vontade' abstrata ao realizarem as suas vontadezinhas 'concretas'...

É aqui que reside o componente positivo (não em juízo de valor, mas no sentido afirmativo, constituinte - e que tem 'materialidade' nos AIE's) da sujeição: o sujeito não é reprimido pela sujeição, pelo contrário, é criado por ela; a pecinha desse sistema de engrenagens é 'abandonada' à sua própria 'vontade', adquirindo 'autonomia', e isso não causa nenhum prejuízo ao funcionamento do maquinário - se a pecinha, que fique claro, 
não estiver defeituosa... - uma vez que aquela 'vontade' é já determinada pelos próprios mecanismos das engrenagens. E se alguma função apresenta defeito, o 'controle de qualidade' da sociedade (o ARE - como sistema de repressão institucional) toma as providências repressivas adequadas: correção, isolamento ou eliminação.

\section{Da 'Reprodução' nas Escolas}

Dentre outras instituições de disciplinamento social, a escola é a que no momento mais nos interessa. Ou antes, nos interessa então o uso que se faz da escola, como uma instituição de Estado que é, e conforme um propósito de se 'formar' as pessoas, que têm de submeter-se à ela. Ou antes ainda, como esse uso se justifica: pelos discursos educacionais que defendem a escola, afirmando que nela se transmite não só bons modelos de conhecimento, mas também bons modelos de comportamento, e para os quais o disciplinamento escolar constitui o eixo necessário à formação do sujeito.

No quadro de funções da escola, deve ser acrescentado o saber comportar-se ao saber fazer. A escola tem uma função disciplinadora, pois é onde as crianças e jovens devem bem aprender o respeito pelos adultos, pelos patrões, pelos chefes de Estado e, é claro, pelo capitalismo e pelas classes sociais nele dominantes. Como escreveu Luckesi, em sua Filosofia da Educação, "o termo 'formação', muito utilizado para definir os fins da atividade escolar, expressa bem o papel de reprodutora do sistema que desempenha a escola. 'Formar' quer dizer 'dar forma a', padronizar segundo modelos" - (Luckesi, 1994, p. 41).

A educação em geral, por si só, será sempre 'reprodutora', pois sempre reproduz algo. O seu problema maior não reside nessa necessidade da reprodução cultural, mas sim naquilo que há por se reproduzir. A escola transmite as ideologias dominantes; é, assim, 'reprodutora' do disciplinamento capitalista. É antiga essa constatação da importância da educação para a manutenção de uma estrutura social. Numa carta de 11 de junho de 1868, enviada a Kugelmann, Marx afirmou que "se uma formação social não reproduz as suas condições de produção ao mesmo tempo que produz, não conseguirá sobreviver um ano que seja" - (cf. Luckesi, 1994, p. 51).

Está na 'essência' da educação o bom cumprimento dos deveres e o não questionar sobre o que fazer. É a nossa herança Iluminista: "Pensai o que quiserdes, contanto que obedeças". Não está em nossa Lei de Diretrizes e Bases da Educação que a escola deve formar cidadãos? Que é ser cidadão senão ser um bom cumpridor de deveres, ser obediente aos patrões e aos aparelhos ideológicos de Estado, pagar suas contas e 
impostos sempre em dia, e acima de tudo, ter respeito pela pátria, com o seu sistema capitalista $e$ as suas injustiças sociais?

Esta nossa atual educação serve ao capitalismo, reproduz seu sistema, seus meios e relações de produção. É impossível que a produção seja mantida sem que se reproduzam seus meios materiais, que garantam a manutenção ou o incremento da produção, assim como tornam necessária a reprodução cultural na sociedade, papel atualmente desempenhado pela escola.

Seria impossível a continuidade da produção sem a reprodução das condições técnicas e materiais (máquinas, equipamentos, recursos) da produção. No entanto, essa reprodução e a sua produção correspondente só se tornam possíveis com um outro elemento fundamental do sistema de produção, objeto mesmo do disciplinamento social educacional: a força de trabalho do proletariado.

A força de trabalho é pois, de duas maneiras, entregue ao sistema produtivo. É entregue pelas forças biológicas, onde a prole é a reprodução do pai. Os operários que, por qualquer motivo, deixam de produzir, precisam ser substituídos por novas forças de trabalho (sua prole). No entanto, do ponto de vista cultural, a força de trabalho deve ser competente; torna-se assim necessária a formação do profissional, segundo os diversos níveis e necessidades da divisão social do trabalho.

A formação profissional e a reprodução cultural da força de trabalho foi socialmente delegada a uma instituição em particular: a escola, que desta maneira tornouse o instrumento principal para a reprodução capitalista. Aprende-se então, nas escolas, uns ditos saberes práticos:

"É pela aprendizagem de alguns saberes contidos na inculcação maciça da ideologia da classe dominante que, em grande parte, são reproduzidas as relações de produção de uma formação social capitalista, ou seja, as relações entre exploradores e explorados, e entre explorados e exploradores. Os mecanismos que produzem esse resultado vital para o regime capitalista são naturalmente encobertos e dissimulados por uma ideologia da Escola universalmente aceita, que é uma das formas essenciais da ideologia burguesa dominante."

- (Althusser, 2001, p. 80.)

Trocando as palavras, o que Althusser quer dizer é que a reprodução da força de trabalho exige não só uma reprodução da qualificação desta, como também uma reprodução da ideologia dominante, para o proletário, e uma reprodução de como manejar a ideologia dominante, para que os agentes da exploração e da repressão, os 
agentes da burguesia (por exemplo: os professores), eles possam assegurar, por meio de sua autoridade e de seus discursos, a dominação imposta pelas classes dominantes, através de elementos difundidos em todos os sistemas da estrutura social.

Os aparelhos ideológicos de Estado são esses elementos, que se mantém a serviço da sociedade e de seus sistemas; podemos citar vários aparelhos, como os religiosos, os escolares, os familiares, os jurídicos, os sindicais, os da informação, os culturais, entre muitos outros. O Estado, com seus aparelhos, é um fator fundamental de manutenção e reprodução da estrutura da sociedade; ele cria assim os mecanismos que perpetuam o sistema.

A escola e outras instituições culturais, como a igreja, a família... ou mecanismos estatais como o exército, não ensinam somente os 'saberes' ditos práticos, mas transmitem modelos, numa tentativa de garantir a sujeição à ideologia dominante, como diria Althusser, ou como bem manejar esta sujeição.

É nas formas e sob as formas da sujeição ideológica que é assegurada a reprodução da força de trabalho do proletariado. A educação legitima os interesses das classes dominantes, reproduz seus valores através da escola, que encarrega-se de transmitir conhecimentos que 'devem' ser tomados como verdades fundamentais, que devem ser assimilados pelos educandos e representados pelos professores.

A escola age por valores e procura aperfeiçoar o sistema dentro do qual está inserida e ao qual serve; é a sociedade que institui a escola e não o inverso, a escola é um instrumento de reprodução e, por isso mesmo, manutenção do sistema vigente. E aqueles que protestarem contra isso serão rapidamente reprimidos e silenciados, quando não mesmo o aquele protesto já não estava condicionado por um sistema, sendo também algo que era até mesmo previsto e aguardado.

E é também o grau de escolaridade de cada um que lhe define o papel a ser ocupado na divisão social do trabalho, algo que é promovido também pela herança cultural, e não apenas pelas diferenças sociais. Os educandos provenientes das classes 'mais altas' geralmente têm mais facilidade de comunicação e uma certa intimidade com a cultura (pois teriam um acesso mais fácil a livros, ao cinema, ao teatro e a outros difusores culturais). Isso lhes dá um repertório que os estimularia aos estudos e a atividades críticas dentro da cultura escolar. Enquanto isso, os educandos das classes 'mais baixas', devido a diversos fatores, como o financeiro (já que muitos têm que trabalhar desde muito cedo, 
sendo assim mais difícil o seu acesso aos meios culturais), apresentam dificuldades em se expressar, pois muitos se deixam intimidar pela divergência de recursos, e dificilmente poderão acompanhar os seus estudos adequadamente.

Os educandos das classes menos privilegiadas, além de terem a sua cultura desclassificada, são obrigados a assimilar uma outra cultura - já que a cultura que lhes é oferecida pela escola é apenas uma cultura das próprias classes dominantes (as mais privilegiadas) - e devem considerá-la como se fosse a única legítima.

Isso tudo aparece como uma espécie de imposição que ocorre em diferentes processos. Essa imposição é facilmente observada nos materiais didáticos, sendo o professor o sujeito/agente principal desta forma de Poder. condicionado pelas ideologias dominantes, controlado pela coordenação pedagógica, pelos diretores das escolas, pelos pais de alunos e, é claro, pelos próprios alunos.

Se prestarmos atenção nos livros didáticos, seremos capazes de perceber a homogeneidade das informações ali contidas (existem livros que trazem os mesmos textos, e são muitas vezes acríticos); quase todos os livros trazem os mesmos conceitos, fábulas e figuras que ilustram sempre as coisas como o sistema capitalista 'pensa' que elas deveriam ser, e não se preocupam com a realidade dos educandos.

Praticamente, só vemos ilustrações de índios e negros em figuras relacionadas com a escravidão e com o passado, como se eles não fossem, hoje, reais. Trazem-nos como uma figura de humilhação e humildade: é como eles deveriam ser, como o capitalismo 'queria' que eles fossem - 'humildes ante sua condição inferior na sociedade', ou melhor, como a nossa cultura diz que eles deveriam ser. As ilustrações que trazem a família são geralmente de famílias felizes: longe do abuso sexual, da violência familiar, da dependência de drogas, dos problemas financeiros... e são freqüentemente famílias de brancos, e com olhos claros... As mulheres são quase sempre relacionadas com o trabalho doméstico e a servidão. As mães são sempre o refúgio para qualquer problema. As ruas são sempre más. O vilão é freqüentemente negro e pobre. O homossexual desaparece. Aliás, o sexo também: só vale para a reprodução.

Essas fábulas são uma maneira gentil de se dizer que qualquer curiosidade, criatividade e transformações serão mal vindas. Assim, a educação não pode trabalhar com a realidade social dos educandos das classes 'baixas'. Os educandos se enchem de culpa, vergonha e medo, tornando-se frágeis, dóceis e socialmente produtivos, ou marginalmente agressivos. Seja como for, qualquer potencialidade 
efetivamente subversiva seria castrada, para o bom funcionamento da socialização, nesta 'sociedade' imposta pelo sistema educacional.

\section{Da Filosofia na Escola 'Reprodutora'}

E a filosofia, a que é 'pregada' nas escolas hoje (pregada, pois assemelha-se, em geral, ao ensino religioso...), quase sempre é uma subespécie de 'educação moral e cívica': acaba servindo para uma transmissão de dogmas religiosos, morais e políticos. Nessa filosofia, cabe ao professor tornar seus alunos 'éticos'; quando a turma não obedece a um professor qualquer, o de filosofia pode ser chamado à coordenação: os seus alunos precisam aprender a Ética! Ou então trata-se a filosofia como uma espécie de ensino religioso, pelo qual devem ser transmitidos os bons preceitos da moral cristã e do amor à família... o que nada mais é senão mais uma forma de se controlar e disciplinar a sociedade.

\footnotetext{
"Adaptada aos tempos atuais, de práticas e produtos light, presenciamos a expansão progressiva de uma forma de pensamento também light, extremamente afastada das pretensões críticas ou fundacionais da velha razão moderna (humana, universal e objetiva). Este pensar, que tem também a pretensão de substituir a razão ilustrada, costuma esgotar-se por completo numa prática servil e tecnocrática, orientada pela busca de uma maior 'eficiência' e uma melhor adaptação às condições dominantes - (...) -, ou então costuma montar uma prédica cética $e$ niilista, com a intenção de desarticular qualquer tentativa que se apresente como um projeto de transformação profunda."
}

- (Cerletti \& Kohan, 1999, p. 46.)

Essa atual filosofia deixa o professor sem possibilidades de ação transformadora, ele não tem como estimular os educandos à criação, sequer ao pensamento crítico ou analítico em relação ao mundo. Antes fosse perigosa, ao invés de contentar-se em apenas refletir e contemplar, sendo assim apenas mais uma forma de sujeição/dominação. É aí (e assim, e por isso mesmo) que deveria entrar a filosofia na escola.

Não que a filosofia seja como uma deusa redentora que nos livrasse dos males sociais; mas ela talvez pudesse atuar na cultura fazendo com que os jovens que estão sendo 'formados' pudessem ter, de alguma maneira, e na pior das hipóteses, alguma ciência do processo no qual estão sendo induzidos. Dizemos induzidos, porque a educação transmite ideologias, que além de justificarem os interesses das classes dominantes, são 
como falsas imagens da realidade, imagens que funcionam segundo os interesses desses alguns, apenas.

A Ideologia perpassa nossas mentes sem que nos demos conta disso; até aqueles que são oprimidos são perpassados pela ideologia que os oprime. É mesmo próprio da Ideologia esse 'apagar' da 'consciência' isso: que ela própria existe devido à alguns interesses. A Ideologia representa o Poder sobre o pensamento. Justamente por ela defender os interesses de algumas classes, criticar a Ideologia significa criticar esses interesses.

Pensamos que a filosofia seja um produto social e cultural, e como tal, que reproduz os valores da sociedade na qual está inserida; mas também que devido a seu caráter de reflexão, inquietação, abertura e desconfiança intelectuais, nem sempre é levada pelas máquinas reprodutoras do sistema vigente. Temos em toda a história da filosofia filósofos que serviriam de exemplo disso, como Karl Marx, Louis Althusser e Alain Badiou, que demarcaram rupturas teóricas com o sistema capitalista. Sobre esse caráter da filosofia, Walter Kohan e Alejandro Cerletti nos dizem que "toda filosofia é uma criatura de seu tempo, e seu caráter se define pela missão que cumpre, por uma marca que deixa na história" - (Cerletti \& Kohan, 1999, p. 82).

Como sugere Cerletti, o 'eixo' da educação deveria ser deslocado do conceito clássico de 'formação' para o de 'transformação' - (cf. Cerletti, in Kohan, 2002, p. 21). Se não é possível abandonar-se o caráter reprodutivista da educação, tratar-se-ia então de melhor definir o que seria reproduzido. E justamente porque a filosofia pode problematizar e questionar os valores e critérios que já são socialmente aceitos e praticados, e intervém, desta forma, na maneira de se ver, conhecer e agir no mundo, é que deveriam ser revistas e revisitadas as aulas de filosofia no ensino médio. Cabe aqui lembrarmos de Bertrand Russel:

"A filosofia, se não pode responder a tantas perguntas como gostaríamos, tem pelo menos o poder de fazer perguntas que aumentam o interesse do mundo, e mostra a admiração e o espanto que se escondem mesmo sob a superfície das coisas mais comuns da vida diária.

"A filosofia deve ser estudada, não para obter respostas a suas perguntas, porque há uma regra que nenhuma resposta definita pode ser comprovada como verdadeira, mas devido a suas próprias perguntas (...)."

- (Russel, apud Cerletti \& Kohan, 1999, pp. 85/86.) 
A filosofia deveria ser feita, também no âmbito educacional, como sendo uma tarefa criadora, em imaginando outras formas de conhecimento, propondo valores diferentes, novos conceitos, criando mundos diferentes. E abandonando, assim, o seu atual papel na cultura, vir a "privilegiar a irrupção do novo frente à conservação do velho, o acaso da liberdade frente à segurança do estado de coisas dominantes, a experiência inédita à prática de normalização ou controle" - (Cerletti, in Kohan, 2002, p. 20). Enfim, para podermos trazer a realidade à sala de aula.

\section{Referências Bibliográficas}

ALTHUSSER, Louis. Aparelhos Ideológicos de Estado. Rio de Janeiro: Graal Editora, 2001.

CERLETTI, Alejandro \& KOHAN, Walter. A Filosofia no Ensino Médio. Brasília: Editora UnB, 1999.

CERLETTI, Alejandro. 'Filosofia/Educação: os desafios políticos de uma relação complicada' In KOHAN, Walter (Org.). Ensino de Filosofia - Perspectivas. Belo Horizonte: Autêntica Editora, 2002.

LUCKESI, Carlos. Filosofia da Educação. São Paulo: Cortez Editora, 1994. 